\title{
Determinants of University Staff Turnover Intention: The Case of Dire Dawa University, Ethiopia
}

\author{
Mesfin Haileyesus* \\ Department of Statistics, College of Natural and Computational Sciences, \\ Dire Dawa University, P.O. Box 1362, Ethiopia \\ Dereje Meretu \\ Department of Statistics, College of Natural and Computational Sciences, \\ Dire Dawa University, P.O. Box 1362, Ethiopia \\ Eshetie Abebaw \\ Department of Statistics, College of Natural and Computational Sciences, \\ Dire Dawa University, P.O. Box 1362, Ethiopia
}

\begin{abstract}
The turnover rate of academic staff in Ethiopian universities has been increasing from time to time. This is aggravated by the increase of brain drain. High employee turnover rates may jeopardize efforts to attain organizational objectives. It indicates that turnover is one of the most expensive and difficult workforce challenges facing organizations. The effect of employee turnover results extra work load on the remaining employees. Increased workload of employees leads to decrease employee morale and increases stress level, which in turn increases employee absenteeism. To identify factors that affects academic staff turnover intention at Dire Dawa University. Data was collected from 154 sample academic staff of the University. To analyze the data Chi-square test and binary logistic regression analysis method was employed. The findings of this study showed that factors such as job satisfaction, job security, salary, allowance/incentive, career growth opportunity, training opportunity, good relationship with Employees and good relationship with head were found to be the significant factors that affect staff turnover intention. However, there is no statistically significant association between turnover intention and factors such as sex, age, marital status, educational level and work experiences of employees.
\end{abstract}

Keywords: - academic staff, staff turnover intention, binary logistic

DOI: $10.7176 / \mathrm{JESD} / 10-17-03$

Publication date:September $30^{\text {th }} 2019$

\section{Introduction}

High employee turnover rates may jeopardize efforts to attain organizational objectives. It indicates that turnover is one of the most expensive and difficult workforce challenges facing organizations. Employee turnover can be extremely devastating for any company (Kemal, 2013). Chen et al. (2010) also state employee turnover as a serious issue, particularly in the area of human resource management. Sometimes employee turnover benefits organizations positively. This might happen when a poor performer is replaced by a more skilled employee and when a retired employee replaced by a younger one. Employee turnover may be also costly as it requires different cost to take account such as administrative costs of recruitment, cost of covering during the period in which there is a vacancy, training cost for the new employee etc (Shamsuzzoha, 2003).

Many factors play a role in the employee turnover rate of any company, and these can stem from both the employer and the employees. Compensation, job satisfaction, leadership style, socio demographic factors, and work environment are some of the factors that play a significant role in employee turnover (Beam, 2009). In addition, worldwide, employees hope to grow their professions and achieve distinguished careers over the course of their work life. Employees believe that their career objectives are within their grasp if they could find the right organization to actualize their ambitions (Weigold, et al., 2013). Organizations, on the other hand, invest heavily in the training, developing, and nurturing of their employees so as to build a stable dependable base for profitability. According to Clarke (2010), the discordant alignment between what employees want and the organizational objectives most often leads to dissatisfaction and eventually employees' turnover.

The effect of employee turnover results extra work load on the remaining employees, on their work performance and an organization's effectiveness. (Mathis and Jackson, 2007) said that those employees who are in the organization have to put extra efforts and have to work extra hours to balance the work of those who left the organization. Increased workload of employees leads to decrease employee morale and increases stress level, which in turn increases employee absenteeism (Ahmed et al., 2016).

In higher education institutions, the importance of academics for quality education is priceless. The members of the academic staff are central to the successful accomplishments of the missions and responsibilities mandated to higher education institutions and goals set to be achieved by them Altbach (2006). When 
employees leave the job, organizations loose not only employee but also lose the customers and clients who were loyal with the employee, knowledge of production, current projects, competitor and past history of the organization (Fahad et al 2010).

In our country Ethiopia a study conducted by Girma et al. (2015) found that family arrangement, lack or low procedural justice, organizational commitment, lack of transport, level of salary, job satisfaction and training opportunity were found to be significantly associated with nurses' turnover intention. In addition, Mulu (2014) showed that overall job satisfaction had a significant effect on commitment of employees and the effect of role stress on job satisfaction and intention to leave is significantly stronger for the female than the male. Furthermore, Shimelis (2016) study revealed that personal factors are not the vital causes for turnover and from pull factors, high salary elsewhere, availability of more financial benefits elsewhere, availability of promotional opportunities external to the hospital and higher educational opportunities are the most important causes initiating medical staffs to leave their job. Hailemichael and Gezahegn (2018) showed female academic staff are 1.492 times more likely to have turnover tendency than male respondents. married academic staffs are 2.088 times less likely to leave their university than their counter parts. The result revealed that academic staffs with a perceived lower salary were 1.231 times more likely intended to leave their Universities.

Although as described above there are several studies that focused on identification of significant factors that affect employee turnover, turnover can be vary in different organization. In addition, to the best of the researchers knowledge there is no published similar study in the study area. Thus, this study intends to identify factors that affects academic staff turnover intention at Dire Dawa University.

\section{Research methodology}

2.1. Study area. The study was conducted in Dire Dawa University (DDU). Dire Dawa University is found in Dire Dawa city. Dire Dawa city is located in eastern part of Ethiopia around $517 \mathrm{~km}$ to the east of the capital Addis Ababa. The city is one of the oldest cities that established as a result of the start of the former Ethio-France rail way transportation company in the year 1903.

2.2. Study Design and Data sources:- A Cross- sectional study design was employed. A primary data was collected between January-February 2019 from the randomly selected academic staff of Dire Dawa University through structured self-administered Questionnaire.

\subsection{Sampling technique and Sample Size Determination}

In this study Stratified random sampling technique was used to select the study participants. Proportional allocation was used to determine the required number of sample from each College/ Institute.

According to Human Resource of Dire Dawa university, in 2018 there were 1196 academic staff not including expatriate staff: 122 staff in College of Natural and Computational Sciences (CNCS), 199 staff in College of Social and Humanity Science (CSHS), 150 staff in College of Business and Economics (CBE), 180 staff in College of Medicine (CM), 37 staff in College of law (CL) and 588 staff in Dire Dawa Institution of technology (DDIT).

Then, the sample size formula stipulated in (Cochran, 1997) was used to get the desired sample size. Since, the researchers have no preliminary information on the values of the population proportion of staff who have intention to quit the present job $(\mathrm{P})$ and its complement $\mathrm{Q}=1-\mathrm{P}$, pilot survey on 30 staff was conducted and the result was used to approximate the values as $P=0.367$ and $Q=0.633$. The level of significance also set as $\alpha=0.05$ and allow margin of error $d=0.07$. Then, the sample size of this study became 158 . Although the researchers distributed 158 questionnaires 4 questionnaires were not returned and it make the response rate $97.4 \%$.

2.4. Variables of the Study. The dependent variable of this study was staff turnover intention (1 if the individual have intention to quit the current job and 0 otherwise). The independent variables were Age, sex, educational level, Marital status, Working experience, satisfied with the current job (no, yes). job is secured (no, yes), work load, salary is good in DDU (no, yes), allowance payment is better in DDU (no, yes), DDU provide career growth opportunity (no, yes), DDU provide necessary training opportunity (no, yes), overall working environment (bad, good), good relationship with employees (no, yes), culture of giving recognition for good work (no, yes) and good relationship with head (no, yes).

2.5. Method of Data Analysis. Descriptive statistics tools such as frequency and percentage was used to present the collected data and to point out special features. Chi-square test was employed to test whether there are statistically significant association between turnover intention and independent factors. Binary Logistic Regression model was fitted to identify significant predictor variables. The level of significance for all the inferential statistics was set at $\mathrm{p}<0.05$.Statistical package for Social Science (SPSS) version 22 was used.

Binary logistic regression model is used if the dependent variable is dichotomous variable. In this study the dependent variable is intention to quit is a dichotomous variable. 
In binary logistic regression, the relationship between the dependent( $\mathrm{Y})$ and independent variables(X's) is not linear. Instead, logit transformation is used and the logistic regression function is expressed in the following form:-

$$
\log \operatorname{it}\left(\mathrm{p}_{\mathrm{i}}\right)=\ln \left[\frac{\mathrm{p}_{\mathrm{i}}}{1-\mathrm{p}_{\mathrm{i}}}\right]=\mathrm{X}_{\mathrm{i}}^{\prime} \beta=\beta_{0}+\beta_{1} \mathrm{x}_{1 \mathrm{i}}+\beta_{2} \mathrm{x}_{2 \mathrm{i}}+\ldots+\beta_{\mathrm{k}} \mathrm{x}_{\mathrm{ki}}
$$

Where:

$$
\mathrm{p}_{\mathrm{i}}=\operatorname{Prob}\left(\mathrm{y}_{\mathrm{i}}=1 \mid \mathrm{X}_{\mathrm{i}}\right)=\frac{\mathrm{e}^{\mathrm{X}_{\mathrm{i}}^{\prime} \beta}}{1+\mathrm{e}^{\prime} \beta}=\frac{\exp \left(\beta_{0}+\beta_{1} \mathrm{x}_{1 \mathrm{i}}+\beta_{2} \mathrm{x}_{2 \mathrm{i}}+\ldots+\beta_{\mathrm{k}} \mathrm{x}_{\mathrm{ki}}\right)}{1+\exp \left(\beta_{0}+\beta_{1} \mathrm{x}_{1 \mathrm{i}}+\beta_{2} \mathrm{x}_{2 \mathrm{i}}+\ldots+\beta_{\mathrm{k}} \mathrm{x}_{\mathrm{ki}}\right)} \quad, \quad \text { is } \quad \text { the }
$$

response probability or probability of success or $\mathrm{Y}=1$.

$\frac{p_{i}}{1-p_{i}}$ is the probability of success to failure or the odds of success.

$\beta_{0}$ is the constant of the equation

$\beta_{\mathrm{i}}$ 's are the coefficients of the independent variables X's. However, in binary logistic regression, the odd ratio $e^{\beta}$ is interpreted.

\section{Data analysis}

Similar to the previous studies that used Turnover intention as actual predictor of Turnover such as Kariuki (2015); Herrbach et al., 2004; Allen et al., 2003 and Griffeth et al., 2000), this study used Turnover intention as a dependent variable. Regarding to intention to quit respondents were asked whether they have intention to quit their current job. The results are given in Table 4.1.

Table 4.1: Intentions to quit

\begin{tabular}{|l|c|l|l|}
\hline Item & Response & Frequency & Percentage \\
\hline Do you have intention to quit the current job? & No & 91 & 59.1 \\
\cline { 2 - 4 } & Yes & 63 & 40.9 \\
\hline
\end{tabular}

As can be seen from Table 4.1, out of the total respondents 91 (59.1\%) of the respondents have no intention to quit their current jobs. However, the remaining 63 (40.9\%) of them have intentions to quit the current job.

As Abdali (2011) stated that the demographic and personnel characteristics of employees include; age, gender, marital status and experience may be reason of leaving from the organization. Accordingly, descriptive statistics of the respondent's demographic characteristics such as respondents sex, age, marital status, educational level and work experience and the cross tabulation with intention to quit are given in Table 4.2.

Table 4.2 showed that out of the total study respondents $143(92.9 \%)$ of them were males and the remaining $11(7.1 \%)$ of them were females. Out of the 143 male respondents $59(41.3 \%)$ of them have intentions to quit the current jobs. Whereas, out of the 11 female respondents $\mathbf{4 ( 3 6 . 4 \% )}$ of them have intentions to quit the current jobs. Regarding age $105(68.2 \%)$ of respondents were aged less than or equal to 30 years and the remaining $31.8 \%$ of respondents were above 30 years old. Out of the 105 respondents who were less than or equal to 30 years old $\mathbf{3 8}(\mathbf{3 6 . 2 \%})$ of respondents have intentions to quit the current jobs. Whereas, out of the 49 respondents who were above 30 years old, $\mathbf{2 5 ( 5 1 . 0 \% )}$ have intentions to quit the current jobs. 
Table 4.2: Cross tabulation of intention to quit and demographic variables

\begin{tabular}{|c|c|c|c|c|}
\hline \multirow[t]{2}{*}{ Variables } & \multirow[t]{2}{*}{ Categories } & \multirow[t]{2}{*}{ Frequency $(\%)$} & \multicolumn{2}{|c|}{ Do you have intention to quit the present job? } \\
\hline & & & $\begin{array}{c}\text { No } \\
\text { Frequency (\%) }\end{array}$ & $\begin{array}{c}\text { Yes } \\
\text { Frequency }(\%)\end{array}$ \\
\hline \multirow[t]{3}{*}{ Age } & $<=30$ years & $105(68.2)$ & $67(63.8)$ & $38(36.2)$ \\
\hline & $>30$ years & 49(31.8) & 24(49.0) & $25(51.0)$ \\
\hline & Total & 154(100) & 91(59.1) & 63(40.9) \\
\hline \multirow[t]{3}{*}{ Gender } & Male & 143(92.9) & 84(58.7) & $59(41.3)$ \\
\hline & Female & 11(7.1) & $7(63.6)$ & $4(36.4)$ \\
\hline & Total & $154(100)$ & 91(59.1) & 63(40.9) \\
\hline \multirow{3}{*}{$\begin{array}{l}\text { Educational } \\
\text { level }\end{array}$} & B.Sc. & $31(20.1)$ & $19(61.3)$ & 12(38.7) \\
\hline & Master's \& above & 123(79.9) & $72(58.5)$ & 51(41.5) \\
\hline & Total & $154(100)$ & 91(59.1) & 63(40.9) \\
\hline \multirow{4}{*}{$\begin{array}{l}\text { Marital } \\
\text { status }\end{array}$} & Single & 67(43.5) & $45(67.2)$ & $22(32.8)$ \\
\hline & Married & $77(50.0)$ & 41(53.2) & $36(46.8)$ \\
\hline & Divorced & $10(6.5)$ & $5(50.0)$ & $5(50.0)$ \\
\hline & Total & $154(100)$ & 91(59.1) & $63(40.9)$ \\
\hline \multirow{3}{*}{$\begin{array}{l}\text { Working } \\
\text { experience }\end{array}$} & $<=5$ years & $89(57.8)$ & 51(57.3) & $38(42.7)$ \\
\hline & more than 5 year & $65(42.2)$ & $40(61.5)$ & $25(38.5)$ \\
\hline & Total & $154(100)$ & 91(59.1) & $63(40.9)$ \\
\hline \multirow{7}{*}{$\begin{array}{l}\text { College } \\
\text { /Institute }\end{array}$} & CNCS & $16(10.4)$ & $11(68.8)$ & $5(31.2)$ \\
\hline & CSSH & $16(10.4)$ & $9(56.2)$ & $7(43.8)$ \\
\hline & CBE & $20(13.0)$ & $12(60.0)$ & $8(40.0)$ \\
\hline & CL & $5(3.2)$ & $3(60.0)$ & $2(40.0)$ \\
\hline & DDIT & $73(47.4)$ & $41(56.2)$ & $32(43.8)$ \\
\hline & CM & $24(15.6)$ & $15(62.5)$ & $16(37.5)$ \\
\hline & Total & $154(100)$ & 91(59.1) & $63(40.9)$ \\
\hline
\end{tabular}

Table 4.2 also showed that out of the total study respondents the majority of respondents $89(57.8 \%)$ of them have less than or equal to 5 years experience. The remaining $65(42.2 \%)$ of respondents have more than 5 years experience. The percentage of respondents who have intentions to quit their current jobs is more or less similar in different categories of work experience. The percentage of respondents who have intentions to quit the current job among respondents who have less than or equal to 5 years experience and above 5 years experience were 42.7 and 38.5 respectively.

Table 4.2 also showed that out of the total study respondents 67 (43.5\%) of them were single, $77(50.0 \%)$ of them were married and the remaining $10(6.5 \%)$ of respondents were divorced. Regarding educational level, out of the total study respondents the majority of respondents i.e. $123(79.9 \%)$ of them have masters degree. The remaining $31(20.1 \%)$ have B.Sc degree. The percentage of respondents who have intentions to quit their current jobs is more or less similar in different categories of educational level and marital status.

Table 4. 3: Cross tabulation of intention to quit and independent variables

\begin{tabular}{|c|c|c|c|c|}
\hline \multirow[t]{2}{*}{ Variables } & \multirow[t]{2}{*}{ Categories } & \multirow[t]{2}{*}{$\begin{array}{l}\text { Frequency } \\
(\%)\end{array}$} & \multicolumn{2}{|c|}{$\begin{array}{l}\text { Do you have intention to quit the present } \\
\text { job? }\end{array}$} \\
\hline & & & $\begin{array}{l}\text { No } \\
\text { Frequency }(\%)\end{array}$ & $\begin{array}{l}\text { Yes } \\
\text { Frequency }(\%)\end{array}$ \\
\hline \multirow[t]{2}{*}{ Satisfied with job } & No & $38(24.7)$ & $10(26.3)$ & $28(73.7)$ \\
\hline & Yes & $116(75.3)$ & 81(69.8) & $35(30.2)$ \\
\hline \multirow[t]{2}{*}{ Job is secured } & No & $54(35.1)$ & $19(35.2)$ & $35(64.8)$ \\
\hline & Yes & $100(64.9)$ & $72(72.0)$ & $28(28.0)$ \\
\hline \multirow[t]{4}{*}{ Work load rate } & Low & 11(7.1) & $6(54.5)$ & $5(45.5)$ \\
\hline & Fair & 46(29.9) & $31(67.4)$ & $15(32.6)$ \\
\hline & High & $56(36.4)$ & $34(60.7)$ & $22(39.3)$ \\
\hline & Very high & 41(26.6) & $20(48.8)$ & 21(51.2) \\
\hline \multirow[t]{2}{*}{ Salary is good at DDU } & No & 64(41.6) & $15(23.4)$ & $49(76.6)$ \\
\hline & Yes & $90(58.4)$ & $76(84.4)$ & $14(15.6)$ \\
\hline \multirow[t]{2}{*}{ Allowance is better at DDU } & No & $92(59.7)$ & $39(42.4)$ & $53(57.6)$ \\
\hline & Yes & $62(40.3)$ & $52(83.9)$ & $10(16.1)$ \\
\hline \multirow{2}{*}{$\begin{array}{l}\text { DDU provide career growth } \\
\text { Opportunity }\end{array}$} & No & $79(51.3)$ & 31(39.2) & $48(60.8)$ \\
\hline & Yes & $75(48.7)$ & $60(80.0)$ & $15(20.0)$ \\
\hline
\end{tabular}




\begin{tabular}{|c|c|c|c|c|}
\hline \multirow[t]{2}{*}{ Variables } & \multirow[t]{2}{*}{ Categories } & \multirow[t]{2}{*}{$\begin{array}{l}\text { Frequency } \\
(\%)\end{array}$} & \multicolumn{2}{|c|}{$\begin{array}{l}\text { Do you have intention to quit the present } \\
\text { job? }\end{array}$} \\
\hline & & & $\begin{array}{l}\text { No } \\
\text { Frequency }(\%)\end{array}$ & $\begin{array}{l}\text { Yes } \\
\text { Frequency }(\%)\end{array}$ \\
\hline \multirow{2}{*}{$\begin{array}{l}\text { DDU provide necessary } \\
\text { Training opportunity }\end{array}$} & No & $65(42.2)$ & $20(30.8)$ & $45(69.2)$ \\
\hline & Yes & $89(57.8)$ & $71(79.8)$ & $18(20.2)$ \\
\hline \multirow{2}{*}{$\begin{array}{l}\text { Overall working } \\
\text { environment }\end{array}$} & $\mathrm{Bad}$ & 89(57.8) & 48(53.9) & 41(46.1) \\
\hline & Good & $65(42.2)$ & $43(66.2)$ & $22(33.8)$ \\
\hline \multirow{2}{*}{$\begin{array}{l}\text { Good relationship with } \\
\text { employees }\end{array}$} & No & $97(63.0)$ & $45(46.4)$ & $52(53.6)$ \\
\hline & Yes & $57(37.0)$ & $46(80.7)$ & 11(19.3) \\
\hline \multirow{2}{*}{$\begin{array}{l}\text { There is culture of giving } \\
\text { Recognition for good work }\end{array}$} & No & $76(49.4)$ & $43(56.6)$ & $33(43.4)$ \\
\hline & Yes & $78(50.6)$ & $48(61.5)$ & $30(38.5)$ \\
\hline \multirow{2}{*}{$\begin{array}{l}\text { Good relationship with } \\
\text { Head }\end{array}$} & No & $95(61.7)$ & $42(44.2)$ & $53(55.8)$ \\
\hline & Yes & $59(38.3)$ & $49(83.1)$ & $10(16.9)$ \\
\hline \multirow{2}{*}{$\begin{array}{l}\text { Immediate family reside in } \\
\text { Dire Dawa }\end{array}$} & No & $116(75.3)$ & $72(62.1)$ & 44(37.9) \\
\hline & Yes & $38(24.7)$ & $19(50.0)$ & $19(50.0)$ \\
\hline
\end{tabular}

Several studies showed that job satisfaction is significantly associated with turnover intention (Pepra-Mensah et al.,2015 and Girma et al.,2015) among others. In addition to job satisfaction, according to Shah (2010), job insecurity is one of the various push factors that initiate employees to quit the current job. Regarding to job satisfaction and job security, respondents were asked whether they are satisfied with their current job and whether they think their job is secured. As showed in Table 4.3, out of the total respondents, $116(75.3 \%)$ of them answered that they are satisfied with their current job. Out of the total respondents, 54 (35.1\%) of them replied that their job is not secured. Regarding the intention to quit differences in job satisfaction categories, out of the 116 respondents who replied that they are satisfied with their current job, 35(30.2\%) of respondents have intentions to quit their current jobs. However, out of the 38 respondents who respond that they are not satisfied with their current jobs, $28(73.7 \%)$ respondents have intentions to quit their current jobs. Whereas, out of the 54 respondents who think that their job is not secured $35(64.8 \%$ ) of respondents have intentions to quit the current job. However, out of the 100 respondents who think that their job is secured, $28(28 \%)$ of them have intentions to quit their current jobs.

As Kariuki (2015) indicates both salaries and bonus payments are key factors influencing employee turnover. Respondents were asked to compare the fairness of their salary and whether they think allowance/incentive payments by Dire Dawa University is better compared to other organizations that they can join as employees. As can be seen from the results in Table 4.3, out of the total study respondents, 64 (41.6\%) of them said that compared to other organizations the salary amount that Dire Dawa University pays is not good. Out of the total respondents, $92(59.7 \%)$ of them said that compared to other organizations the allowance/incentive payments at Dire Dawa University is not better. Table 4.3 also showed that out of the 64 respondents who said their salary in Dire Dawa University is not good, 49(76.6\%) of respondents have intentions to quit their current jobs. Whereas, out of the 90 respondents who said their salary in Dire Dawa University is good, 14(15.6\%) of them have intentions to quit their current jobs. Regarding - allowance/incentive payments, out of the 92 respondents who said their allowance/incentive payments in Dire Dawa University is not better, 53(57.6\%) of respondents have intentions to quit their current jobs. Whereas, out of the 62 respondents who said their allowance/incentive payments in Dire Dawa University are better, 10(16.1\%) respondents have intention to quit the current job.

Table 4.3 also showed the percentages of respondents who have intention to quit their current jobs do not vary much along different categories of workload rate. The percentages of respondents who have intention to quit their current jobs among respondents that rated their work load as low, fair, high and very high are 45.5, 32.6, 39.3 and 51.2 respectively.

Lack of career advancement and training opportunities in the organization may initiate an employee to quit thier jobs. Girma et al. (2015) showed that training opportunity is significantly associated with nurses' turnover intention. Shimelis (2016) revealed that lack of career advancement triggers staff turn-over. Regarding career growth and training opportunities, respondents were asked whether there are regular opportunities of career advancement and training opportunities in the university. As showed in the Table 4.3, out of the total respondents, $79(51.3 \%)$ of them responded that Dire Dawa University does not provide regular opportunities for career advancement. Out of the total respondents, $65(42.2 \%)$ of them do not think that Dire Dawa University provides necessary training opportunities. The remaining 55 (34.0\%) of respondents answered that Dire Dawa University provides necessary training opportunities. Out of 79 respondents that thought Dire Dawa University does not provide regular opportunities of career advancement, $\mathbf{4 8}(\mathbf{6 0 . 8} \%)$ of them have an intention to quit their current jobs. Whereas, out of the 75 respondents that thought Dire Dawa University does provide regular opportunities of career advancement, only $\mathbf{1 5}(\mathbf{2 0 . 0} \%)$ of them have an intention to quit their current jobs. Out of 65 respondents who replied that Dire Dawa University doesn't provides necessary training opportunities, 45(69.2\%) of them have 
an intention to quit their current jobs. Whereas, out of 89 respondents who think Dire Dawa University provides necessary training opportunities, only $\mathbf{1 8}(\mathbf{2 0 . 2} \%)$ of them have an intentions to quit their current jobs.

In addition, Table 4.3 showed that among those 76 respondents who did not agree on the presence of a culture of giving recognition for their good work, 33(43.4\%) of respondents have intention to quit their current job.

Table 4. 4: Chi-Square Test Statistics of the variables

\begin{tabular}{|l|l|l|l|}
\hline Independent Variables & $\begin{array}{l}\text { Pearson } \\
\text { Chi-Square value }\end{array}$ & df & $\begin{array}{l}\text { Asymp. Sig. } \\
\text { (2-sided) }\end{array}$ \\
\hline Gender & .101 & 1 & .750 \\
\hline Age & 3.040 & 1 & .081 \\
\hline Educational level & .078 & 1 & .780 \\
\hline Marital status & 3.236 & 2 & .198 \\
\hline Work experience & .279 & 1 & .598 \\
\hline College/ Institute & 1.054 & 5 & .958 \\
\hline Job satisfaction & 22.418 & 1 & $.000^{*}$ \\
\hline Job security & 19.660 & 1 & $.000^{*}$ \\
\hline Load of work & 3.269 & 3 & .352 \\
\hline Salary & 57.586 & 1 & $.000^{*}$ \\
\hline Allowance/ incentive & 26.363 & 1 & $.000^{*}$ \\
\hline Career growth opportunity & 26.441 & 1 & $.000^{*}$ \\
\hline Training opportunity & 37.320 & 1 & $.000^{*}$ \\
\hline Working environment & 2.321 & 1 & .128 \\
\hline Good relationship with Employees & 17.483 & 1 & $.000^{*}$ \\
\hline Culture recognition & .392 & 1 & .531 \\
\hline Good relationship with Head & 22.713 & 1 & $.000^{*}$ \\
\hline Family resident & 1.725 & 1 & .189 \\
\hline
\end{tabular}

Chi-square test of association or independence was employed to test whether there are statistically significant association between employee turnover intention and independent variables of the study. The results of the test are given in Table 4.4. As can be seen from Table 4.4, variables such as job satisfaction, job security, salary, allowance/incentive, career growth opportunity, training opportunity, good relationship with Employees and good relationship with head were found to be significantly associated with turnover intention at $5 \%$ level of significance. However, no statistically significant association were found between turnover intention and variables such as gender, age, marital status, educational level, College/ Institute, work experience, work load, family residents, working environment and culture of giving recognition for good work at 5\% level of significance.

Binary Logistic Regression model was fitted to identify the major significant predictor variables of employee turnover intention. All of the independent variables that are found to be statistically significant in Chi-square test were included in the binary logistic regression model that contains several (multiple) independent variables. The results of the Binary Logistic Regression model are given in Table 4.6. the model summary given in Table 4.5 showed that Nagelkerke R square $=0.798$ indicates that $79.8 \%$ of variation in the dependent variable intention to quit is expressed the independent variables included in the model. The Hosmer and lemeshow test that was used for checking goodness of the fitted model showed that the $p$-value is 0.953 . This $p$-value 0.953 is greater than the level of significance 0.05 implying that there is no significant difference between the observed and expected value. Therefore the model is good fitted model.

Table 4. 5: Model summary

\begin{tabular}{|c|c|c|c|c|c|}
\hline \multirow{2}{*}{-2 Log likelihood } & Cox \& Snell & Nagelkerke R & \multicolumn{2}{|c|}{ Hosmer and Lemeshow Test } \\
\cline { 4 - 6 } & R Square & Square & Chi-square & df & Sig. \\
\hline 70.277 & .592 & .798 & 2.670 & 8 & .953 \\
\hline
\end{tabular}

As the results of the Binary Logistic Regression model given in Table 4.6 showed, variables such as job satisfaction, job security, salary, allowance/incentive, career growth opportunity, training opportunity, good relationship with Employees and good relationship with head were found to be significant at $5 \%$ level of significance. 
Table 4. 6: Results of Binary Logistic regression Model

\begin{tabular}{|c|c|c|c|c|c|}
\hline Variables & Categories & $\mathrm{B}$ & S.E. & $p$-value & $\operatorname{Exp}(B)$ \\
\hline \multirow[t]{2}{*}{ Satisfied with job } & No & 1.487 & .729 & $.041 *$ & 4.424 \\
\hline & Yes & & & & 1 \\
\hline \multirow[t]{2}{*}{ Job is secured } & No & 1.654 & .681 & $.015 *$ & 5.229 \\
\hline & Yes & & & & 1 \\
\hline \multirow[t]{2}{*}{ Salary is good at DDU } & No & 1.978 & .645 & $.002 *$ & 7.231 \\
\hline & Yes & & & & 1 \\
\hline \multirow[t]{2}{*}{ Allowance is better at DDU } & No & 1.909 & .718 & $.008 *$ & 6.745 \\
\hline & Yes & & & & 1 \\
\hline \multirow{2}{*}{$\begin{array}{l}\text { DDU provide career growth } \\
\text { Opportunity }\end{array}$} & No & 2.075 & .717 & $.004 *$ & 7.965 \\
\hline & Yes & & & & 1 \\
\hline \multirow{2}{*}{$\begin{array}{l}\text { DDU provide necessary } \\
\text { Training opportunity }\end{array}$} & No & 2.056 & .691 & $.003 *$ & 7.816 \\
\hline & Yes & & & & 1 \\
\hline \multirow{2}{*}{$\begin{array}{l}\text { Good relationship with } \\
\text { employees }\end{array}$} & No & 1.395 & .699 & $.046 *$ & 4.036 \\
\hline & Yes & & & & 1 \\
\hline \multirow{2}{*}{$\begin{array}{l}\text { Good relationship with } \\
\text { Head }\end{array}$} & No & 1.611 & .736 & $.029 *$ & 5.010 \\
\hline & Yes & & & & 1 \\
\hline \multicolumn{2}{|c|}{ Constant } & -7.711 & 1.330 & $.000 *$ & .000 \\
\hline
\end{tabular}

As showed in Table 4.6, the estimated odd ratio of employee who is not satisfied with his/her job is 4.424. This imply that the probability of having intention to quit job for employee who is not satisfied with his/her job is 4.424 times higher than employee who is satisfied with his/her job (reference group) controlling for the other covariates in the model.

The estimated odd ratio of an employee who feels that his/her job is not secured is 5.229. This shows that an employee who feels that his/her job is not secured has a 5.229 times higher probability of having intention to quit job than employee who feel that his/her job is secured (reference group) controlling for other covariates in the model.

The estimated odd ratio of an employee who feels that salary at Dire Dawa University is not good is 7.231. This imply that the probability of having intention to quit job for an employee who feels that salary at Dire Dawa University is not good is 7.231 times higher than for employee who feels that salary at Dire Dawa University is good (reference group) controlling for other covariates in the model.

The estimated odd ratio of an employee who feels that allowance/incentive payment at Dire Dawa University is not better is 6.745 . This imply that the probability of having intention to quit job for an employee who feels that allowance/incentive payment at Dire Dawa University is not better is 6.745 times higher than for employee who feels that allowance/incentive payment at Dire Dawa University is better (reference group) controlling for other covariates in the model.

The estimated odd ratio of an employee who thinks Dire Dawa University does not provide regular opportunities of career advancement is 7.965. This shows that an employee who thinks Dire Dawa University does not provide regular opportunities of career advancement has a 7.965 times higher probability of having intention to quit job than employee who thinks Dire Dawa University does provide regular opportunities of career advancement (reference group) controlling for other covariates in the model.

The estimated odd ratio of an employee who thinks Dire Dawa University does not provide a necessary training opportunity is 7.816. This shows that an employee who thinks Dire Dawa University does not provide a necessary training has a 7.816 times higher probability of having intention to quit job than employee who thinks Dire Dawa University does provide a necessary training opportunity (reference group) controlling for other covariates in the model.

The estimated odd ratio of an employee who has no good relationship with employees is 4.036. This imply that the probability of having intention to quit job for an employee who have no good relationship with employees is 4.036 times higher than for employee who have good relationship with employees (reference group) controlling for other covariates in the model.

The estimated odd ratio of an employee who has no good relationship with his/her head is 5.010. This imply that the probability of having intention to quit job for an employee who has no good relationship with his/her head is 5.010 times higher than for employee who has good relationship with his/her head (reference group) controlling for other covariates in the model.

\section{Discussion}

The findings of this study agree with a study conducted by Shimelis (2016) that revealed personal factors are not the vital causes for turnover. However, these findings contradict the findings of Abdali (2011). Abdali (2011) 
stated that the demographic and personnel characteristics of employees that include age, gender, marital status and experience may be reasons of leaving from the organization. The finding of this study also contradicts Hailemichael and Gezahegn (2018). Hailemichael and Gezahegn (2018) revealed that gender and marital status are significant.

The finding of this study agreed with the suggestion of Pullins and Fine (2002). Pullins and Fine (2002) suggested that employee's relation with the supervisor adversely influences the propensity for employee turnover.

This study also found that career growth and training opportunities are significantly associated with turnover intention. These results are consistent with the previous studies that showed career growth and training opportunity affect turnover Intention (Puah and Ananthram, 2006); Girma et al. (2015) and Katamba (2011).

The finding of this study agreed with studies that showed job satisfaction is significantly associated with turnover intention (Pepra-Mensah et al., 2015and Girma et al., 2015). However, this study disagrees with Mwendwa (2017). Mwendwa (2017) found that job satisfaction did not influence employees intention to quit. The current study findings agreed with Shah (2010). According to Shah (2010) job insecurity is one of the various push factors that initiate employees to quit the current job.

Regarding to salary and allowance/ incentive, the study agree with Kariuki (2015). Kariuki (2015) indicated that both salaries and bonus payments are key factors influencing employee turnover.

\section{Conclusions and recommendations}

\subsection{Conclusion}

The results of this study found that variables such as job satisfaction, job security, salary, allowance/incentive, career growth opportunity, training opportunity, good relationship with Employees and good relationship with head were found to be significant.

The probability of having intention to quit job for employee who is not satisfied with his/her job is 4.424 times higher than employee who is satisfied with his/her job. An employee who feels that his/her job is not secured has a 5.229 times higher probability of having intention to quit job than employee who feel that his/her job is secured. Compared to employee who feels that salary at Dire Dawa University is good, the probability of having intention to quit job is 7.231 times higher for an employee who feels that salary at Dire Dawa University is not good. Similarly the probability of having intention to quit job for an employee who feels that allowance/incentive payment at Dire Dawa University is not better is 6.745 times higher compared to employee who feels that allowance/incentive payment at Dire Dawa University is better.

An employee who thinks Dire Dawa University does not provide regular opportunities of career advancement has a 7.965 times higher probability of having intention to quit job than employee who thinks Dire Dawa University does provide regular opportunities of career advancement. Similarly an employee who thinks Dire Dawa University does not provide a necessary training has a 7.816 times higher probability of having intention to quit job compared to employee who thinks Dire Dawa University does provide a necessary training opportunity. The probability of having intention to quit job is also higher for an employee who have no good relationship with employees and his/her head.

\subsection{Recommendations}

In order to reduce or tackle the problem of employee turnover in Dire Dawa University, this study recommends the following:

The significance of training opportunities and allowance/incentive payments indicates that the management should search a way to provide both training opportunities and allowance/incentive payments to employees. These can be possible if the management first, initiate all departments of the University to plan training programs that they can possibly deliver to the rest of the community. Then, work for the realization of the proposed training programs by easing bureaucracy and consider incentives for the trainers.

Employee job satisfaction and job security directly have an effect on employee retention. Thus, in order to increase employees job satisfaction and ease job insecurity, it will be better if the management consider increasing employees participation in making decisions, providing necessary facilities, training and upgrading programs to the employees and acknowledging high performer employee.

The current study showed that relationship with employees and head are significant. Thus, the management should exert efforts to create good working environment. Organizing get-togethers may help.

Funding: The authors received no direct funding for this research. However, Department of Statistics provides all costs of questionnaire duplication and printing.

Data Availability

The data to support the findings are available from the corresponding author upon request.

Conflicts of Interest

The authors declare that they have no conflicts of interest. 


\section{References}

Abdali, F .2011. Impact of Employee Turnover on Sustainable Growth of Organization in Computer Graphics Sector of Karachi, Pakistan, Afro Asian Journal of Social Sciences, 2 pp 2-3.

Ahmed, Z., Sabir, S., Khosa, M., Ahmad, I., Bilal. 2016. Impact of Employee Turnover on Organisational Effectiveness in Tele Communication Sector of Pakistan.IOSR Journal of Business and Management (IOSRJBM). PP 88-96.

Allen, D.G., Shore, L.M. and Griffeth, R.W. 2003. The Role of Perceived Organizational Support and Supportive Human Resource Practices in Turnover Process. Journal of Management, 29, 99-118.

Altbach, P. G. (2006). Comparative Higher Education: Knowledge and Development. Boston: Boston College

Beam, J. 2009. What is Employee Turnover? Retrieved June 10, 2018, from Wise GEEK:http//www.wisegeek.com/what is employee turnover

Chen, M.-F., Lin, C.-P., \& Lien, G.-Y. 2010. Modeling job stress as a mediating role in predicting turnover intention. The Service Industries Journal, 1743-9507.

Clarke, T. A. 2010. Retention, turnover and return - a longitudinal study of Allied Health Professionals in Britain. Human Resource Management Journal, 391-406.

Cochran, G.W. 1977. Sampling techniques, $3^{\text {rd }}$ Edition.John Wiley \& Sons, Inc.

Fahad et al (2010). Factors affecting employees retention: evidence from literature; Abasyn Journal of Social Sciences. Vol.4 No.2 pgs $307-339$.

Girma Alem, Erdaw Betre and Habtamu Abera. 2015. Assessment of Factors Affecting Turnover Intention AmongNurses Working at Governmental Health Care Institutionsin East Gojjam, Amhara Region, Ethiopia. American Journal of Nursing Science, 4(3): 107-112

Griffith, R.W., \&Hom, P.W. 2001. Retaining Valued Employees. London, Sage Publication

Griffeth, R.W., Horm, P.W. and Gaertner, S. 2000. Meta-Analysis of Antecedents and Correlates of Employee Turnover: Update, Moderator Tests, and Research Implications for the Next Millennnium. Journal of Management, 26, 463-488.

Hailemichael and Gezahegn .2018. Determinants of Turnover Intention of Employees Among the Academic Staffs (The Case of Some Selected Ethiopian Universities). Journal of Economics and Sustainable Development. ISSN 2222-1700 (Paper) ISSN 2222-2855 (Online). Vol.9, No.15, 2018

Herrbach, O., Mignonac. K. and Gatignon, A-L. 2004. Exploring the Role of Perceived External Prestige in Managerse Turnover Intentions. International Journal of Human Resource Management, 15, 1390-1407.

Kariuki, Phedis W. 2015. Factors affecting employee turnover in the banking industry in kenya: a case study of imperial bank limited. United states international University.

Katamba H. S. 2011. Factors Affecting Voluntary Nursing Staff Turnover in Mengo Hospital (Master's Thesis). University ofSouth Africa.

Kemal M. 2013.The Negative Effect and Consequences of Employee Turnover andRetention on the Organization and Its Staff.European Journal of Business and Management www.iiste.orgISSN 2222-1905 (Paper) ISSN 2222-2839 (Online)

Mathis, R. L. \& Jackson, J. H., 2001, Human Resource Management, 9 th ed, South Western College Publishing

Mulu Berhanu. 2014. Factors affecting academic staff turnover intentionsand the moderating effect of gender. International Journal of Research inBusiness Management, Vol. 2, 57-70

Mwendwa, J.M. 2017. Determinants of employee intention to quit their jobs at commercial banks in Kenya a case study of kcb bank Kenya limited. A Research Project Report Submitted to the School of Business in Partial Fulfillment of the Requirement for the Degree of Masters in Organizational Development (MOD). UNITED STATES INTERNATIONAL UNIVERSITY- AFRICA

Pepra-Mensah, Josephine. Luther NtimAdjei and Kate Yeboah-Appiagyei. 2015. The Effect of Work Attitudes on Turnover Intentions in the HotelIndustry: The Case of Cape Coast and Elmina (Ghana). European Journal of Business and Management, Vol.7, No.14, 114-122

Puah, P., \&Ananthram, S. 2006. Exploring the antecedents and outcomes of career development initiatives: Empirical evidence from Singaporean employees. Research and Practice in Human Resource Management, 14, 112-142.

Shamsuzzoha, A. 2003.Employee Turnover-a Study of its Causes and Effects to Different Industries in Bangladesh. Doctorial Dissertation, University of Vaasa, Finland.

Shimelis Tsehayu. 2016. Causes and Consequences of Medical Staff Turnover the Caseof Menelik II Referral Hospital: in Addis Ababa. MA Thesis. Addis Ababa University, Addis Ababa, Ethiopia.

Weigold, I. K.,Porfeli, E. J., \&Weigold, A. 2013. Examining tenets of personal growth initiative using the personal growth initiative scale-II. Psychological Assessment, 25(4), 1396-1403. Retrieved from http://dx.doi.org/10.1037/a0034104 